10.1515/ausfm-2015-0009

\title{
Intermediality between Games and Fiction: The "Ludology vs. Narratology" Debate in Computer Game Studies: A Response to Gonzalo Frasca
}

\author{
Michalis Kokonis \\ Aristotle University, Thessaloniki, Greece \\ E-mail: kokonis@enl.auth.gr
}

\begin{abstract}
In the last ten or fourteen years there has been a debate among the so called ludologists and narratologists in Computer Games Studies as to what is the best methodological approach for the academic study of electronic games. The aim of this paper is to propose a way out of the dilemma, suggesting that both ludology and narratology can be helpful methodologically. However, there is need for a wider theoretical perspective, that of semiotics, in which both approaches can be operative. The semiotic perspective proposed allows research in the field to focus on the similarities between games and traditional narrative forms (since they share narrativity to a greater or lesser extent) as well as on their difference (they have different degrees of interaction); it will facilitate communication among theorists if we want to understand each other when talking about games and stories, and it will lead to a better understanding of the hybrid nature of the medium of game. In this sense the present paper aims to complement Gonzalo Frasca's reconciliatory attempt made a few years back and expand on his proposal. ${ }^{1}$
\end{abstract}

Keywords: intermediality, ludology, narratology, semiotics, stories, computer games, gameplay, God-games.

The rapid development of digital technologies and the widespread use of computers are signs of radical changes in life, especially in popular culture and entertainment. As a result of the spectacular growth of computer games in culture, a shift in entertainment patterns has been observed. It seems that more and more

1 A similar and slightly different paper is under publication in Greek in the Proceedings of the 10th International Conference of Semiotics: Changing Worlds and Signs of the

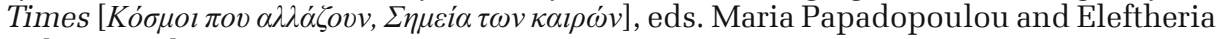
Deltsou, Volos, Greece. 
people show a preference for playing electronic games ${ }^{2}$ over watching movies or TV, reading books, or listening to music. As recent research statistics show [Fig. 1] (The NPD group, 2013), the percentage of computer games users has risen significantly compared to the other, more traditional forms of entertainment, such as movies, TV series, recorded or live music.

Similar reports e.g. from the Entertainment Software Association (ESA) provide statistics that dissolve the myth that computer games "are just for kids," or they are "about shooting aliens." According to the ESA report the average age of the videogame player is 30 years, whereas interesting figures are presented in findings about the gender and age range of players: $32 \%$ of users are under 18, $32 \%$ have an age ranging from 18 to 35 , while an impressive $36 \%$ designates players above 36 years old. Another interesting demographic is that the gender of players is divided between $55 \%$ for men and $45 \%$ for women, but women over 18 represent a greater percentage (31\%) compared to boys under 17 , which is only 19\% [Fig. 2] (http://www.theesa.com/facts/pdfs/ESA_EF_2013.pdf).

Such statistics reveal a shift in entertainment patterns and point to the spectacular rise of a cultural phenomenon, the growing popularity of computer games, a fact that has not escaped the attention of cultural critics. Indeed, the map of media studies in the academy has changed since Computer Games Studies has been established as an autonomous field of study in higher education, with New Departments being set up in European and North American Universities, World or International Conferences about Computer Games being organized, and relevant academic journals being published.

Espen Aarseth, one of the pioneers in the field, entitled his article "Computer Games Studies, Year 1” (2001b), thus inaugurating officially the study of Computer Games as an independent and legitimate academic discipline. Henry Jenkins (2000) declared Computer Games to be "the art form of the digital age" that deserves the same kind of critical attention given so far to the traditional art forms of the $20^{\text {th }}$ century. Roy Shuker (1995), even more enthusiastically, considers computer games "a major cultural form" and predicts that they "may well soon replace cinema, cable and broadcast television as the dominant cultural form." Finally, Jesper Juul (2000) remarks that although we still "have not seen the first videogame Shakespeare or Bach," yet "the speed with which videogames have developed aesthetically, formally and functionally, is remarkable.” (All the above critics are cited in Newman 2004, 2.)

2 The use of the terms computer games, videogames, or electronic games is equivalent; therefore they are used interchangeably. 
However, on the research level there has been observed an animosity between two rival groups of critics, resulting in an almost ten-year long and on-going debate over the most appropriate methodological approach for the study of computer games: on the one hand, the so-called narratologists (or narrativists) ${ }^{3}$ find affinities between computer games and the traditional storytelling arts and approach games for their narrative dimension; on the other hand, the ludologists ${ }^{4}$ focus attention on the mechanics of the functions of computer games and reject an analysis of computer games as narratives. Their basic argument is that the story elements in a game, if any, are of no real importance, as the gamer is the least interested in them; his or her main concern being with gameplay itself, namely how to win the game. Narratologists, on the other hand admit that some games have nothing to do with stories, but the most popular ones, those that are launched in the market as blockbusters, ${ }^{5}$ have a strong narrative element or share common characteristics with Hollywood blockbusters, and as a result they go about researching aspects of visual representation, the notion of movement, narrative space and time, character narrativity, animation techniques, etc. (King and Krzywinska 2002, 3).

This theoretical clash, which has been going on for quite some time now, seems to have been triggered by the radical, and sometimes extreme positions held on the camp of ludologists who feared that the newly established discipline of computer game studies would be overwhelmed by a neo-colonial discourse and could be annexed as a subfield of English, Literature, or Media Studies. Hence Aarseth's early plea in his article (2001b) to let Computer Game Studies flourish as an autonomous and independent academic field, and be free from any colonization attempts by scholars with a background in Humanities, Cultural, or Media Studies. Markku Eskelinen (2001) went a step further in making an overtly polemical comment that "in the best cases stories in videogames are just uninteresting elements or gift wrappings to games," which was quoted by Rune Klevjer, and then by three other

3 Michael Mateas (2002, 32) suggests the term narrativist for the new narratologists who study digital based narratives and thus computer games to distinguish them from the classic narratologists (Barthes, Todorov, Genette, Greimas, Metz, Prince) whose theories had appeared long before the advent of computer games.

4 From the latin "ludus," meaning play controlled by rules. Gonzalo Frasca (2003) explains how the term came to be first used in the $3^{\text {rd }}$ International conference on Digital Art and Culture at Brown University (2001) in reference to the keynote speakers Eskelinen, Juul, and Frasca and since then it has been adopted to denote researchers in electronic/digital/computer game studies.

5 To give an indication, only $5 \%$ of the 6000 games produced and circulated in the global market every year achieve commercial success (King and Krzywinska 2002, 8). But they have the greatest sales, dominating the game market. 
commentators, adding to the animosity between the two rival camps. Commenting on the difference between games and narrative, Richard Rouse said that "What a player primarily seeks in the gaming experience is the challenge they offer, his/her total immersion in the gameplay, the need for action and not simply to watch. [...] The player demands more interaction with the game, while the narrative parts are tiresome" (2003, 2-13). Concerning the issue of interaction, not only Rouse, but also Chris Crawford, as well as Loftus and Loftus, reached the extreme position equating response to narrative with passivity as opposed to the active role of player in interaction with games. Loftus and Loftus's statement on interactivity is characteristic: "When reading a narrative or watching a movie the reader/spectator follows the fantasy of the story passively, whereas the player in computer games undertakes a more energetic role in the gameworld" $(1983,41)$.

In an attempt to bridge the theoretical schism Gonzalo Frasca (2003) wrote a reconciliatory article entitled "Ludologists love stories too: notes from a debate that never took place," as a sort of apology for the hard-line radicalism of his colleagues and in order to explain that the so-called debate between narratologists and ludologists is the result of some misconceptions and misunderstandings. Therefore he urges his readers to consider this debate as never really have taken place. Nowhere in the ludologists' publications, he claims, there is any evidence of an intention to downgrade narrative or to disparage narratologists. He simply expressed the ludologists' belief that in computer games it is not story but gameplay which has central role, and therefore approaching computer games study from the perspective of game theory is a viable methodology which they are not inclined to abandon. As for the extreme and radical positions, like that expressed by Eskelinen, Frasca tried to explain it away saying that no offence was intended by the Finnish ludologist and that his statement was misconstrued.

The aim of this article ${ }^{6}$ will be to complement Frasca's reconciliatory purpose, moving past the surface debate level to address the core of the problem. Endorsing his constructivist spirit we will have to agree that the so-called Narratology vs. Ludology Dilemma is a false one and that this debate will have to be resolved, as it is of no help to the cause of establishing Computer Games Study as an autonomous and independent academic field. We will accept that this debate came about due

6 The present article is the result of an earlier study in Greek, Kokonis (2010, 338-401). In this study an attempt is made to deal with the cultural phenomenon of computer games in the digital age and a critical stance is expressed to Frasca's position. Also a more specific proposal to overcome the methodological dilemma in Computer Game Studies has been presented in the $10^{\text {th }}$ International Conference of Semiotics (see Note 1 above), which is under publication. 
to misunderstandings and misconceptions, as it usually happens in the beginning of a new phenomenon, like the appearance of computer games on the cultural scene. And we will have to agree that the theoretical chasm between researchers, scholars and critics must be bridged, if we want to understand each other when talking about games and stories and, above all, if we want to comprehend games as a new cultural and popular art form.

Overcoming the rivalry between the theoretical camps, after the necessary concessions are made from each side, will not suffice however, as long as the methodological problem is not resolved. Placing computer games in an intermedial context it becomes apparent that we are dealing with a new cultural form that is largely based on digital technologies. As a result, it is a hybrid form that seems to combine elements from the more traditional art forms with new traits that derive from its digital technological base. If we just for a moment consider how computer games utilize the computer screen, the nature and extent of this hybridity will become apparent. In the sense expressed by Bolter and Grusin, computer games employ the videogame screen both as a means of immediacy and hypermediacy: on one hand the screen is transparent, guiding our view like a window inside the gameworld and facilitating immersion in it; on the other it becomes hypermedial, dividing its surface into various parts that function as multiple channels of communication and interaction with the user, as the game's principal means of interface. Thus computer games remediate the screen of other media in the following ways:

a) As a monitor: computer games borrow the function of the screen from surveillance systems especially in the category of shoot them up games, where the player, as some kind of guard, surveys the space before him and shoots up any intruders.

b) From live TV: computer games borrow the function of TV live transmission and remediate it in games played in real time.

c) From the Cinema Screen: Ever since the development of 3D graphics, computer games have acquired the narrative function of cinematic images, borrowing realistic representation and movement from the cinema screen, so that the gamer has the possibility of immersion in the fictional gameworld, while at the same time the intricate interface allows the player to interact physically with the game's interface (gameplay).

d) From the world of computers: Computer games borrow the metaphor of the desktop, incorporating in the game veritable computer traits such as top-down menus, page scrolling, hypertext buttons, etc. (2000, 88-94). 
Thus, computer games studies is a relatively new and uncharted critical territory precisely because it is based on digital technology. If we approach the subject with interest and without prejudice, we may discover that the theoretical tools of the past are not as reliable in research as we used to think. Perhaps, both narratologists and ludologists should reconsider that neither narratology nor ludology alone are sufficient for the study of the phenomenon. What is needed is a wider, more flexible theoretical grid that it would incorporate both the narratology and the ludology perspectives, as well as other theoretical tools, for the comprehensive study of computer games. I would suggest semiotics to be used as an umbrella theory scheme which would allow for a revision of the narratological aspect of story in computer games, as well as the application of ludology for the role of the play and game element in the structures of gameplay and an assessment of the user's interaction with the game. In this way, we could arrive at a better understanding of the nature of play in computer games and comprehend them as a cultural form of expression.

\section{Some Preliminary Notes and Concessions}

I would like to begin with some observations or minor objections to certain points made in Frasca's article. First, considering the use of the terms "ludologist" and "ludology," I would suggest that these terms should be thought in a wider sense than what ludologists envision them today. The term "ludologist" should not be limited to exclusively designate the researcher who explores the mechanism of the computer games. It should be extended to cover the research of games in general, whether traditional or contemporary, old or new, analog or digital. Similarly the term "ludology," ditto, should not be limited or be a synonym for the study of electronic games. The definition of "ludology" given by Frasca (1999) as "the study of games in general and of videogames in particular," which is not different than the first definition of the term tabulated in the electronic journal Game Research.com as "the study of games, particularly of computer games," offers the margins for a wider sense of the term. I find objectionable, though, the second definition of the term provided by Game Reseearch.com: "Ludology is often defined as the study and function (gameplay) of games, in contrast to the study of games as narratives or the study of games as a visual medium." There are games that function as narratives, or at least narrative is a vital part of their structure. Besides, practically all games work thanks to their graphic

$7 \quad$ See: http://game-research.com/index.php/dictionary/. Last accessed 15. 10. 2013. 
representation (computer graphics). Therefore, such a definition is limiting and simplistic. To establish Ludology as an academic discipline it would require a broadening of its scope for both the synchronic and diachronic study of all kinds of play and game, taking recourse to the tenets of classical Play and Game Theory as expressed by the pioneers in the field, e.g. Huizinga, Caillois, Avedon and Smith, and others. It is already encouraging the fact that Markku Eskelinen has expressed the need to draw on classical Play and Game Theory in his essay "The Gaming Experience” (2001, n.p.).

Secondly, I think that Ludologists need not to barricade themselves behind radical or extreme positions, because within the rhetoric of a polemical discourse the real target of research, that is, what is the nature of computer games, what are their inherent characteristics, what is the way or the degree of their user's interaction with them, might go amiss. As several commentators have pointed out, Computer Games Studies is at its initial stage of research, and the first, timid steps are now being made towards the medium's specificity. Newman for example, has defined five basic elements as computer games' inherent characteristics: graphics, sound, interface, gameplay, and story $(2004,10-11)$. If narratologists set out to explore the narrative dimension of a game with story, as its starting point in their approach, and ludologists respectively focus on gameplay to discuss the gaming experience, there remain three other traits that could very well require a different theoretical approach: theories of representation, aesthetics or perception for computer graphics; theories about the transmission and reception/function of sound for the audio aspect of games; and theories of the new digital media for the issue of interactivity regarding the interface/mode of communication of the games with their user. These are all good reasons why a broader and wider theoretical scheme is necessary to accommodate all of the particular theoretical approaches, giving the opportunity to researchers with a different theoretical background and expertise to contribute to this affair.

I will return to this issue shortly with a more specific proposal, but at the moment I would like to voice some thoughts concerning the camp of narratologists. Given that computer games are not experienced as narratives in the way that novels, movies, and TV series are, I think it fit to suggest that narratologists should also make the concession that some other theoretical perspective, other than narratology, could be welcome in Computer Games Studies. Besides, narratologists should respect Aarseth's request to abstain from any imperialistic attempt to colonize the subject as a part of literary, cinema, or media studies. Already King and Krzywinska, in the introduction to the volume ScreenPlay that 
they have co-edited, declare their intention to examine only games with a distinct narrative dimension and to focus on the common elements games share with cinema. They emphatically state that "this is not designed to be an 'imperialist' enterprise, seeking to claim the relatively unsettled territory of games largely or exclusively for film-oriented approaches" $(2002,3)$.

Finally, why not reverse the tables and claim that ludology (in the wider sense proposed above) could become a useful tool for the study of literary and cinematic narratives? The affinity between play and fiction has been pointed out by scholars and critics in the past who observe that many literary texts have a playful character. Indicatively, I refer to some titles in the relevant bibliography that demonstrate such an affinity: Hutchinson, P. (1983) Games Authors Play (Methuen); Detweiler, R. (1976) "Games and Play in Modern American Fiction" Contemporary Literature, XVII: 45-62; Bruss, E. (1977) "The Game of Literature and Some Literary Games" New Literary History, 9: 153-72. The play element in fiction can be found on various levels: at the level of style, e.g. in poems with rhymes, puns, metaphors, etc. Any text by Nabokov is notorious for its language games. Also in terms of plot, especially in detective fiction, the antagonism between author and reader is more than obvious regarding the discovery or not of the criminal before closure. Mostly the element of play and game is obvious in intertextuality, i.e. in texts where the emphasis does not lay in the relationship of the text with the external world, but in the relationship with other fictional texts. We are then talking about cases of metafiction in which the author's aim is not simply to create a story but to offer additional commentary on the nature of the narrative text and on narrative conventions. In the comparative study of my Ph.D Thesis entitled "Metafictional Games: The Play Element in Cinema and the Novel” (1991), which was written much before there was any concern with the study of computer games, the aim was precisely to consider the role of play or game both in literary metafiction texts (e.g. Kurt Vonnegut, Jr, John Barth, William Gass, John Fowles, Raymond Federman, Donald Barthelme, Vladimir Nabokov, Italo Calvino, and others), as well in cinematic texts (e.g. Alfred Hitchcock, Jean Luc Goddard, Francois Truffaut, Frederico Fellini, Brian DePalma, Woody Allen, Richard Rush, Mel Brooks, and others). Play and Game Theory proved instrumental in examining the relationship between authors and their texts or readers/viewers and their texts. I bring up this piece of information just to show that both narratology and ludology do not exclude one another, but instead can combine in the study of texts, including videogames as texts. 


\section{Semiotics as a Viable Methodology Tool}

I take the chance now to make a specific proposal about semiotics that will provide a wider theoretical framework. But before I suggest a particular semiotic model for the study of games, an answer is needed for the question "why semiotics?" From a purely pragmatic point of view, what the gamer faces on the screen before him or her is just some shapes, colours, designs, objects, and movements. Playing the game means assigning some meaning to each one of them, configuring them out, which means treating them as signs that need interpretation. In combination to each other, then these lead to further signs, which also need interpretation, as part of an on-going process in the semiotic chain of signs, what C. S. Pierce calls a spiral of semiosis. When approaching a computer game through a semiotic perspective, we observe that meaning derives or is produced by the process of signs that, when interpreted, induce the gamer to further action. The game as text then offers itself up for examination as a field "where interpretation and action must always be seen as living in a closely co-ordinated working relationship since signs are both the result and the ground of all kinds of action" (Compagnio and Coppock 2009, 8).

Semiotics has not been applied in Computer Game Studies until recently, either because computer games is a relatively new cultural form, or because members of the international semiotic community initially thought that the hybrid, technologically based computer games would not comprise a de facto object of study as do the more traditional literary or audiovisual texts that structural semiotics had taught us to treat as texts. Nevertheless, some semioticians believe that given the appropriate semiotic model computer games too could be subject to semiotic analysis, as Compagnio and Coppock of the Italian semiotic Association suggest in the new semiotic journal E/C Journal (2009). The model of semiotics they propose offers a new perspective for the examination of contemporary cultural forms and tendencies, as it is based on a conception of semiotics, "more pragmatic and modern," that derives from "a plane or level of analysis that seeks 'immanent,' hermeneutic traces or structures" in the relation of the semiotic text with the interactive, perceptual, and hermeneutic functions and practices of its user (Compagnio and Coppock 2009, 6). In short their brand of semiotics offers "a framework that builds on a dynamic distinction between text and practice" $(2009,2)$.

On the other side of the Atlantic American scholars have been active in researching semiotic systems for application in computer games studies. Most notable is the work of David Myers, who is said to have worked on the semiotics for computer games longer than anyone else. Myers focuses his research on 
computer games language and the aesthetics of computer games in a manner analogous to that of Russian formalists who defined literariness in literary works.

However, it seems to me that the semiotic model of "text vs. practice" proposed by the Italian semioticians is more amenable for the study of computer games. It offers a wider theoretical framework that allows for the involvement of partial theoretical approaches, e.g. narratological, ludologist, or other, in the analysis of computer games' inherent characteristics. At the same time it is a pragmatic framework, since by focusing on the relation between the text and its user, offers the appropriate perspective to assess key theoretical issues such as narrativity or interaction, which mark any similarities or differences existing between computer games viewed as texts with the more traditional narrative texts.

\section{God-Games: A Case Study}

More specifically, of the various games genres (action, adventure, sports, simulations, puzzle games, role-playing games, etc.) we could single out computer strategy games, which according to the ESA report are of the most popular (39\%), to use as case study for the application of the semiotic model "text vs. practice." Particularly the games combining simulation with strategic action with four basic aims of the type $4 \mathrm{x}$ (eXplore, eXpand, eXploit, eXterminate), which develop on turn-based moves on a map but combine real-time tactics and provide the player with a point of view from above, enabling him to control the world of the gameplay (thus the name God-Games), are the best games for a case study.

We could have chosen action games like Max Payne (Remedy/God Games 2001) or games like the Die Hard trilogy (Probe, Fox Interactive 1996), obviously a franchise of the respective film series, where the narrative dimension is more obvious, with a distinct story taking a central role and being followed faithfully during gameplay. But games of simulation and strategy like Command and Conquer (Electronic Arts, 1999), or Sid Meyers' Civilization series (Microprose 1989, 1996, Infogrames 2001, 2KGames 2005), comprise a category where the narrative dimension is not prominent, as the purpose in such games is the development of a people or nation (economic, political, military) in antagonism with rival nations, where the player achieving absolute hegemony becomes the winner. Unlike action games that are plot-driven with main characters and a protagonist-hero, in God Games the hero is the map itself, that is, the game-text that the player has to traverse from one territory to the next until all provinces and countries are conquered and the player is proclaimed absolute ruler. 
A typical example of a game combining simulation and strategy is Rome: Total $W_{a r}{ }^{T M}$ (Sega/Activision, The Creative Assembly, 2004) (to be referred to as $R T W$ from now on). It is a simulation, as every time it is played, a new version of History of Hellenistic and Early Roman times is recreated (270 BC to 14AD). At the same time it is a strategy turn-based game with real-time battle action. There is not a particular story determining the flow and evolution of the game, other than the historical evolution and progress of a faction the player plays with. Finally, the story that is created by the player's moves at the game's closure is the historical account of a small city-state of the antiquity from its humble beginnings to its gradual development into an immense empire stretching around the Mediterranean. History is being (re-) written with a capital H. In fact, the game's structure provides 9 factions (17 if the player mods the game) to compete against each other, which gives this game a great flexibility, so that it is not always the glory of Rome that is recreated in the simulation of historical reality. Instead the player may choose to lead any of Alexander the Great's successors, such as Kassander of Macedonia, the Seleucids of Antioch, the Ptolemies of Egypt, or even Hannibal of Carthage, the Gauls, the Parthians, or the Dacians for that matter, producing a counterfactual historiography. In this sense, the game is similar to Close Combat II: A Bridge Too Far (Microsoft 1996), which is a real-time strategic war-game, simulating a counterfactual historiography by "rewriting the History of the Second World War to the advantage of Nazi Germany" (Atkins 2003, 2).

I am not going to engage in a full analysis of RTW's game text. Instead I will simply try to illustrate how its signs are deciphered in the on-going chain of spiral semiosis and how the semiotic brand of "text vs. practice" opens up the text for examination through divergent theoretical approaches e.g. from a narratological, or ludic perspective, etc. For this purpose I am going to cite from one screenshot of a game that was in progress, a "page" so to speak from the game text. As shown in Fig. 3, the player has chosen to lead the Carthaginians, who seem to be winning in the game. The screenshot in Fig. 3 depicts the Campaign Map of Greece, as the current theatre of operations, in its main section (Section A from now on), and the bottom part is divided into three more sections: Section B which shows the entire ancient world with all of its 103 provinces; in the middle bottom section, Section C a full Carthaginian army is presented with three generals and several military units including hoplites, war elephants, archers, and cavalry; and finally in the right bottom part, Section D there are icons that work as hypertextual buttons as part's the game's intricate interface. All four Sections of the screenshot are replete with signs which may signify individually or in combination with each other, 
not only within their section, but through all sections. To explain their mode of signification I will rely on the Piercian tri-partied semiotic model, whereby each sign has three aspects: the iconic, the indexical, and the symbolic. For example, in the geophysics map of Section A, we notice some parts of the Greek mainland, as well as parts up north in the Balkans, where mountains are snow-capped; this climate detail is conveyed through the iconic aspect of the sign. In addition, this sign relates to the icon of a snowflake in Section D, which is a sign signifying also the season through its symbolic aspect.

Signs can be meaningful in various ways. Some signs, and the aspects thereof, may pertain to the representation mode; others may relate to story, or gameplay; there are signs that are functional, like the snowflake icon above, as parts of the game's interface; finally, others may pertain to the auditory part of the game, for instance its music, speech parts, or sound effects. (Every time there is an update report in the form of a top-down scroll of the faction's treasury, the clinging of coins is heard.) To give a satisfactory and comprehensive account of the ways signs communicate meaning, we will need to employ Roland Barthes's five narrative codes: the hermeneutic, the proairetic, the semic, the cultural or referential code, and the symbolic code (S/Z 1970, 17-18). Signs with an iconic aspect are usually interpreted with the cultural or referential code, often in combination with the hermeneutic or the proairetic code, and thus pertain to the representational mode, to the story or the gameplay: in Section A, the Greek peninsula, with its mountains, plains, cities, ports, parts of Asia Minor, the Aegean and Ionian seas, war ships, commercial vessels, the Greek cities of Corinth, Athens, Larissa, Thermon, Apollonia, Thessaloniki, Pergamum, etc. are easily recognizable and knowable from our storehouse of prior knowledge. The same applies to iconic aspects of signs in Section B (we recognize countries, areas, seas, etc.) and similarly we comprehend the army with its generals, the military units, with their uniforms, equipment, etc. in Section C. Through the symbolic code we read the $3 \mathrm{~d}$ sculpture representation of Zeus in Olympia, in the Peloponnese, as a sacred site, as well the half-moon in the white banners of the Carthaginian armies, with the indexical aspect of the sign signifying a full army when the white turns to grey. The white banners of Carthaginians signify as an index of their presence in foreign territories, contributing to the hermeneutic code that explains their actions: so they have conquered most of the west, including Rome, and are now heading (proairetic code) towards capturing the rest of the Greek Cities. Such information conveyed by the signs are vital both to the development of the story, and to the gameplay. The full army designated by the icon of the soldier carrying the grey 
flag is lead by the general Thero Ibera. We gather this piece of information by relating the iconic sign of his portrait in Section B, in combination with the legend "Thero Ibera" in Section D. The green colour extending from the Peloponnese up to Macedonia, is the indexical aspect of the sign related to the same general, who is advancing on the way from Athens to Larissa. This is read through the semic code: it is interpreted as part of the game's interface to let the user know the extent of the army's movement in a single move; also, the grey colour on the flag can be read through the proairetic code: it indicates to the user that this is a powerful army capable of capturing a walled city like Larissa. Therefore Thero Ibera is most probably moving against Larissa.

It is, therefore, by means of such complex reasoning, the outcome of the chain of meaning in the spiral of the process of semiosis that the gamer traverses the text. By interpreting the basic signs, which incite to action, and then the combination of signs enable further interpretations that facilitate gameplay and narrative development. Thus the game text opens up for a critical analysis that could involve additional theoretical approaches: for instance, starting with the interpretation of iconic signs the critic could focus on issues of representation to discuss immersion in the gameworld; or with the help of the hermeneutic, proairetic, or symbolic code one might probe into the narrative dimension and argue for instance that in God-Games particularly, there may be not only one story, but four of them; ${ }^{8}$ similarly, another researcher could utilize the relevant codes and interrogate the text from a ludology perspective: degrees of antagonism in the game, the role of chance, even role-playing.

\section{Conclusion}

Endorsing Frasca's proposal to bridge the theoretical gap in the so-called narratology vs. ludology debate and expanding on it, the present article proceeds to address the core of the methodological problem in Computer Games Studies. From the discussion made it transpires that, instead of excluding one another, both narratology and ludology could join forces to dissolve the dilemma. It became also

8 James Paul Gee made this point in his lecture at the University of Melbourne. First the Back-up, or the Designers story which is used to just set the implicit narrative, so that the game does not play in a vacuum; then the player's story which is the trajectory of moves of the map: this is more important because it helps the shaping and completion of the text; then the player's career story: the skills accumulated by the player to start from novice to expert level; finally, the creation of virtual stories, the numerous versions of the historical fact (counterfactual as well), with the difference that the player does not create them as historian, but as God Almighty. 
obvious that due to the hybrid, technology based medium of computer games, a wider theoretical framework is necessary, flexible enough to encompass divergent theoretical perspectives in the critical analysis of videogame texts. The brand of semiotics "text vs. practice" proposed here fulfils this purpose. It will allow the contribution of both narratology and ludology, or any other relevant theoretical perspective to enable the researcher investigate crucial issues, such as the role of narrative in computer games, the type or degree of interaction with the user, issues of immersion in the gameworld, etc., problems that were the cause for the debate in the first place. Eventually Computer Games Studies may evolve as an academic discipline to help understand the nature of computer games as a new cultural form.

\section{References}

Aarseth, Espen J. 2001. Computer Game Studies, Year One. Game Studies. vol. 1, no.

1. http://www.gamestudies.org/0101/editorial.html. Last accessed 25. 03. 2014.

Aarseth, Espen. 1997. Perspectives on Ergodic Literature. Baltimore, MD.

Atkins, Barry. 2003. More Than a Game: The Computer Game as Fictional Form.

Manchester and New York: Manchester University Press.

Avedon, Elliott Morton and Brian Sutton-Smith. 1971. The Study of Games. London: John Wiley \& Sons.

Barthes, Roland. 1977. S/Z. An Essay. Trans. Richard Miller. New York: Hill and Wang.

Bolter, D. J. and R. Grusin. 2000. Remediation: Understanding New Media. Cambridge, MA: MIT.

Bruss, Elizabeth. 1983. The Game of Literature and Some Literary Games. New Literary History vol. 9: 153-72.

Caillois, Roger. 1961. Man, Play and Games. Trans. Meyer Barash. New York: The Free Press.

Compagnio, Dario and Patrick Coppock. 2009. Introduction: Computer Games: Between Text and Practice. E IC Journal (Serie Speciale). Associazione di Studi Semiotica. Anno III, no. 5: 5-11. http://www/.ec-aiss.it/monografici/5_ computer_games.php. Last Accessed 25. 03. 2014.

Crawford, Chris. 1984. The Art of Computer Game Design. htpp://www.vancouver. wsu.edu/fac/peapody/game-book/Coverpage.html. Last Accessed 25. 03. 2014. Detweiler, Robert. 1976. Games and Play in Modern American Fiction. Contemporary Literature XVII: 45-62. 
Entertainment Software Association. 2013. Essential Facts about the Computer and Video Game Industry. The ESA Report. p. 2. http://www.theesa.com/facts/ $p d f S / E S A \_E F \_2013 . p d f$. Last accessed 30. 03. 2014.

Eskelinen, Markku. 2004. From Markku Eskelinen's Online Response. First Person: New Media as Story, Performance, and Game, eds. N. Wardrip-Fruin and P. Harrigan, 120-121. Cambridge, MA: MIT Press.

Eskelinen, Markku. 2001. The Gaming Situation. Game Studies 1. http://www. gamestudies.org/. Last accessed 30. 03. 2014.

Eskelinen, Markku and R. Tronstad. 2003. Video Games and Configurative Performances. In The Video Game Theory Reader, eds. M. J. P. Wolf and B. Perron, 195-220. London: Routledge.

Frasca, Gonzalo. 2003. Ludologists Love Stories Too; Notes from a Debate That Never Took Place. Paper presented at the Level Up: Digital Games Research Conference, Utrecht. In Level Up: Digital Games Research Conference Proceedings, eds. Marinka Copier and Joost Raessens, 92-99. Utrecht: DiGRA and University of Utrecht.

Frasca, Gonzalo. 1999. Ludology Meets Narratology: Similitude and Differences between (Video) Games and Narrative. htpp://www.jacaranda.org/frasca/ ludology.htm. Last accessed 28. 02. 2014.

Gee, Paul James. 2006. Part 3: Games as Literacy. A Productive Approach to Video Games, Learning, and School. Lecture delivered at the Centre for Educational Media, Monash University, Melbourne, on Saturday 19, August. http://www.youtube.com/watch?v=_2gpuD_sro\&feature=relmfu.

Last accessed 10. 12. 2013.

Huizinga, Johan. 1970. Homo Ludens: A Study of the Play Element in Culture. Trans. R. C. F. Hull. New York: Harper and Row.

Hutchinson, Peter. 1983. Games Authors Play. London and New York: Methuen. King, Geoff and Tanya Krzywinska, eds. 2002. ScreenPlay: Cinema / Videogames / Interfaces. London and New York: Wallflower Press.

Kokonis, Michalis. 2012. The Reader as Author and the Ontological Divide: Rome Total War ${ }^{\mathrm{TM}}$ and the Semiotic Process. Gramma/Гра́ $\mu \alpha$ : A Journal

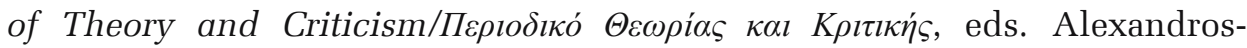
Faedon Lagopoulos, Karin Boklund-Lagopoulou. School of English, Aristotle University of Thessaloniki: University Studio Press.

Kokonis, Michalis. 1991. Metafictional Games: The Play Element in Cinema and the Novel. Ph.D Dissertation. School of English, Aristotle University of Thessaloniki. Thessaloniki, Greece. 


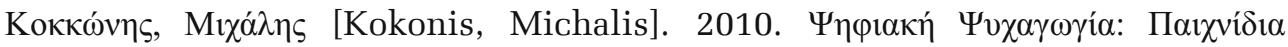

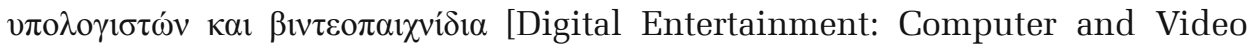

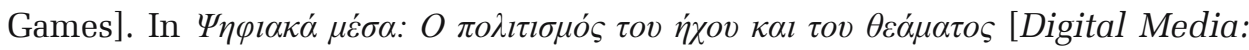
The Culture of Sound and Spectacle], eds. Michalis Kokonis, Philemon Bantimaroudis, and Grigoris Paschalidis, 339-399. Athens: Kritiki Publications.

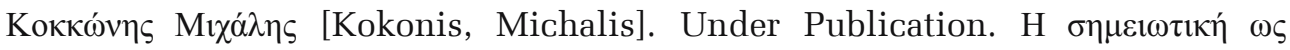

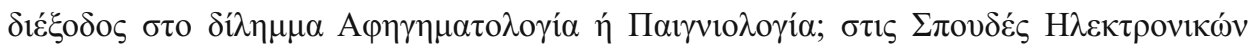

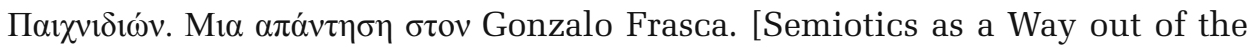
Dilemma: Narratology or Ludology? in Computer Game Studies. A Response to

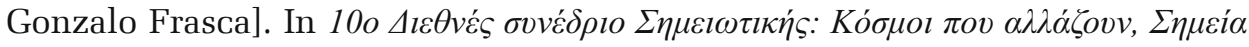

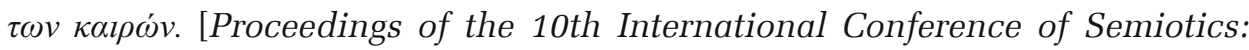
Changing Worlds and Signs of the Times], eds. Maria Papadopoulou and Eleftheria Deltsou. Hellenic Semiotic Society.Volos, Greece.

Loftus, G. R. and E. F. Loftus. 1983. Mind at Play: The Psychology of Video Games. New York: Basic Books.

Mateas, Michael. 2002. Interactive Drama, Art and Artificial Intelligence. Ph.D Dissertation. Technical Report CMU-CS-02-206. School of Computer Science, Carnegie Mellon University, Pittsburgh, PA. http://reports-archive.adm. cs.cmu.edu/anon/2002/CMU-CS-02-206.pdf. Last accessed 15. 05. 2009.

Mäyrä, Frans. 2008. An Introduction to Game Studies: Games and Culture. London: Sage Publications.

Myers, David. 2003. The Nature of Computer Games: Play as Semiosis. New York: Peter Lang.

Myers, David. 2010. Play Redux: The Form of Computer Games. Ann Arbor: The University of Chicago Press and the University of Michigan Library. http:// fileshare3090.depositfiles.com/auth13534004320bbc8ac44ec372ce9238eb46.177.56.90-669299696-62341957-guest/FS309-6/0472050923PlayRedux.rar. Last accessed 18. 10. 2013.

Newman, James. 2004. Videogames. London and New York: Routledge.

NPD Group, The. March 2013. Entertainments Trends in America. https://www.npd.com/latest-reports/entertainment-trends-2013/?utm source=IndustyExpertise\&utm_medium=Link\&utm_campaign=LatestReports Last accessed 18. 10. 2013

Peirce, C. S. 1932. Collected Papers. Vol. I and II. Cambridge, MA: Harvard University Press, 1931-1958. 
Rome: Total War ${ }^{\mathrm{TM}}$, Gold Edition. Activision / Sega, The Creative Assembly, 2004. Rouse, Richard. 2001. Game Design: Theory and Practice. Plano, Texas: Wordware Publishing.

\section{List of Figures}

Figure 1. The NDP Group report on Money Spent monthly on Entertainment.

\section{Percent Share of Monthly Spend on Content}

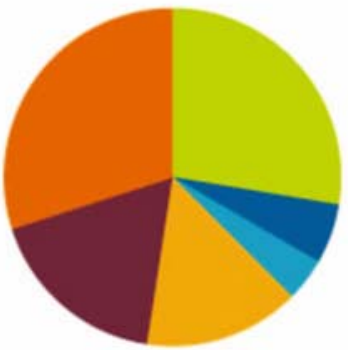

- Video Games

- Movie/TV Show purchase

- Movie/TV Show Rental

- Movie Tickets

= Recorded Music

- Music Concerts

Figure 2. Age and gender specific statistics of game players.

\section{The average age of game players is:}

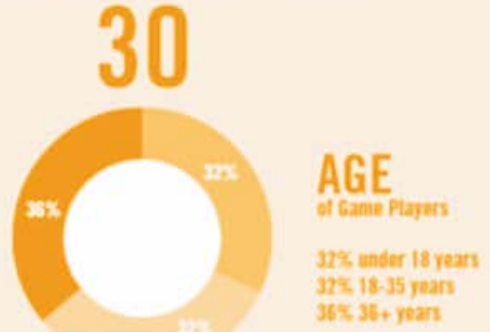


Figure 3. The Campaign Map RTW (screenshot).

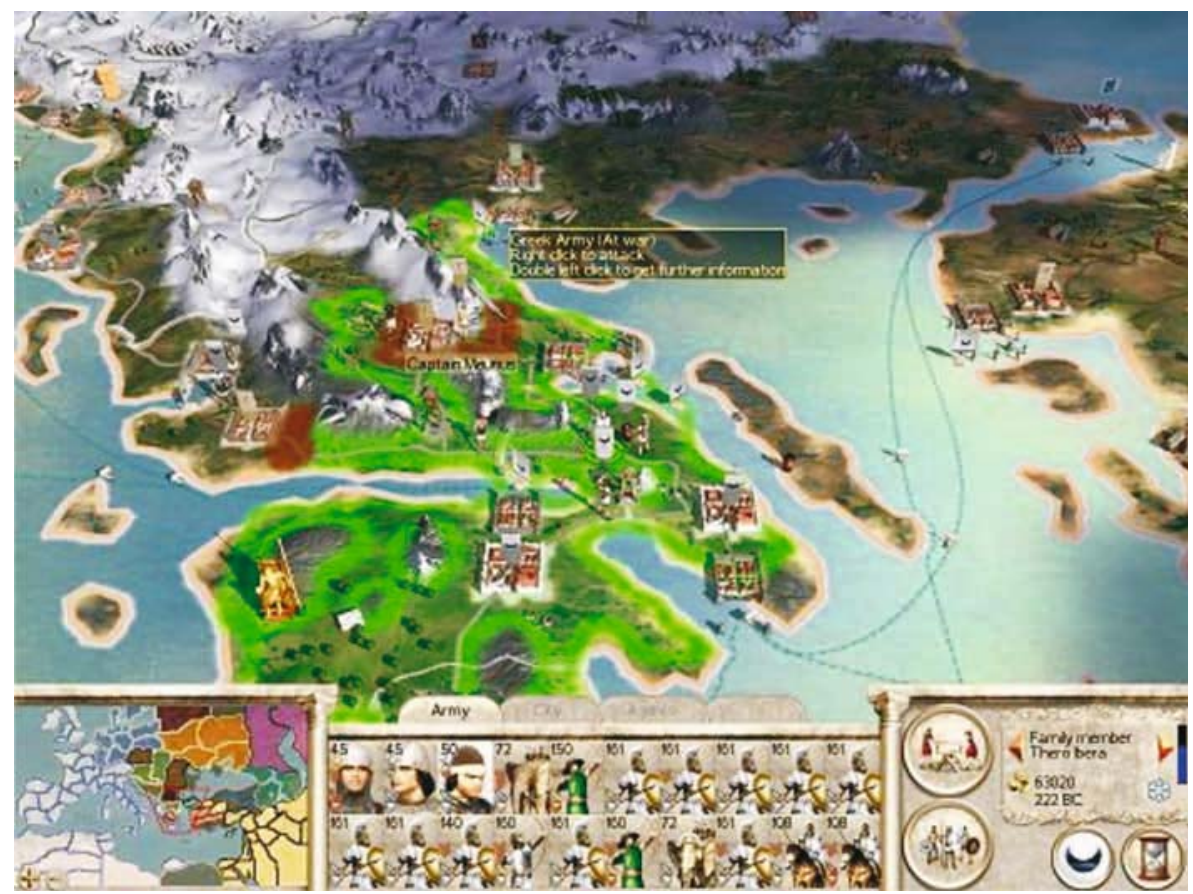

Source: Heavengames.com. Rome Total War: The Strategic Map 